\title{
CLIMATE AND LIFE-HISTORY EVOLUTION IN EVENING PRIMROSES (OENOTHERA, ONAGRACEAE): A PHYLOGENETIC COMPARATIVE ANALYSIS
}

\author{
Margaret E. K. Evans, ${ }^{1,2}$ David J. Hearn, ${ }^{1,3}$ William J. Hahn, ${ }^{4,5}$ Jennifer M. Spangle, ${ }^{6,7}$ and \\ D. LAWRENCE VENABLE ${ }^{1,8}$ \\ ${ }^{1}$ Department of Ecology and Evolutionary Biology, Biological Sciences West, Room 310, University of Arizona, \\ Tucson, Arizona 85721 \\ ${ }^{2}$ E-mail: mekevans@yahoo.com \\ ${ }^{3}$ E-mail: hearn_dj@yahoo.com \\ ${ }^{4}$ Georgetown College, 108 White-Gravenor, Georgetown University, Washington, D.C. 20057 \\ ${ }^{5}$ E-mail: wjh22@georgetown.edu \\ ${ }^{6}$ Genomic Analysis and Technology Core, Biological Sciences West, Room 246, University of Arizona, Tucson, Arizona 85721 \\ ${ }^{7}$ E-mail: spanglej@email.arizona.edu \\ ${ }^{8}$ E-mail:venable@u.arizona.edu
}

\begin{abstract}
Evolutionary ecologists have long sought to understand the conditions under which perennial (iteroparous) versus annual (semelparous) plant life histories are favored. We evaluated the idea that aridity and variation in the length of droughts should favor the evolution of an annual life history, both by decreasing adult survival and by increasing the potential for high seedling survival via reduced plant cover. We calculated phylogenetically independent contrasts of climate with respect to life history in a clade of winter-establishing evening primroses (sections Anogra and Kleinia; Oenothera; Onagraceae), which includes seven annuals, 12 perennials, and two variable taxa. Climate variables were quantified from long-term records at weather stations near collection localities. To explicitly account for phylogenetic uncertainty, contrasts were calculated on a random sample of phylogenetic trees from the posterior distribution of a Bayesian analysis of DNA sequence data. Statements of association are based on comparing the pertree mean contrast, which has a null expectation of zero, to a set of per-tree mean contrasts calculated on the same trees, after randomizing the climate data. As predicted, increased annual aridity, increased annual potential evapotranspiration, and decreased annual precipitation were associated with transitions to the annual habit, but these trends were not significantly different from the null pattern. Transitions to the annual habit were not significantly associated with increases in one measure of aridity in summer nor with increased summer drought, but they were associated with significantly increased maximum summer temperatures. In winter, increased aridity and decreased precipitation were significantly associated with transitions to the annual habit. Changes in life history were not significantly associated with changes in the coefficient of variation of precipitation, either on an annual or seasonal (summer vs. winter) basis. Though we cannot attribute causality on the basis of a correlational, historical study, our results are consistent with the idea that increased heat and drought at certain times of the year favor the evolution of the annual habit. Increased heat in summer may cause adult survival to decline, while increased aridity and decreased precipitation in the season of seedling recruitment (winter) may favor a drought-avoiding, short-lived annual strategy. Not all of the predicted patterns were observed: the capability for drought-induced dormancy may preclude change in habit in response to summer drought in our study group.
\end{abstract}

Key words._-Aridity, Bayesian analysis, iteroparity, phylogenetic uncertainty, semelparity.

Received November 29, 2004. Accepted May 31, 2005.

A fundamental axis of life-history variation concerns the number of reproductive bouts per lifetime, or biomass allocation to reproduction per bout. Some organisms reproduce just once in their lifetime, allocating so much biomass to reproduction that subsequent chances of survival are nil (known as semelparity or monocarpy). Others reproduce more than once per lifetime and allocate less to offspring production per bout (known as iteroparity or polycarpy).

Evolutionary ecologists have long sought to understand the conditions under which one of these reproductive strategies should be favored over the other. Following Cole (1954), we consider the problem in terms of annual versus perennial plant life histories (like Cole, we use the term "perennial" to refer to iteroparous perennials). In particular, we focus on the evolution of a significant class of annual plants, desert annuals. Annuals make up a large fraction of desert floras (Raunkiaer 1934; Daubenmire 1968; Crawley 1997; Gurevitch et al. 2002). In North America, for example, about $50 \%$ of plant species in the Sonoran, Mojave, and Chihuahuan Deserts are annual (Daubenmire 1978; Venable et al. 1993; Dimmitt 2000).
Demographic models predict that low survival of adults (perennating plants that have reproduced at least once) and high survival of seedlings (prereproductive individuals) should favor evolution of the annual habit (Charnov and Schaffer 1973; Bell 1976; Young 1981; Young and Augspurger 1991; Roff 1992, 2002; Stearns 1992; Charlesworth 1994; Silvertown and Charlesworth 2001). Schaffer and Gadgil (1975) suggested that the annual habit is favored in deserts because extreme aridity and droughts of variable lengths (a high coefficient of variation of precipitation, correlated with extreme aridity) make it difficult for perennating organs to survive, whereas annual seed banks are more resistant to such stress. It also has been suggested that annuals are favored in deserts because of the abundance of open space, which makes it possible for seedling survival to be higher than it can be in closed canopy environments (Schaffer and Gadgil 1975; Crawley 1997; Dimmitt 2000; Silvertown and Charlesworth 2001). The same harsh conditions in deserts that make perennial plant survival difficult generate open space available for seedling recruitment. Seedling survival 
TABLE 1. Ecological information for taxa in the sections Anogra and Kleinia of the genus Oenothera (Onagraceae). Standard abbreviations are used for state names in the United States (BCN refers to Baja California Norte, Mexico); lowercase letters before such abbreviations indicate ordinate directions. Life history is either annual (A), perennial (P), or biennial (B). The citations for life history (in superscript) are: (1) Klein 1970; (2) Pavlik and Barbour 1988; (3) Wiggins 1980; (4) Wagner 1998; (5) Klein 1962; (6) Martins and Hutchins 1980; (7) Welsh et al. 1987; (8) Munz 1931; (9) McGregor and Barkley 1986; (10) Correll and Johnston (1970); and (11) Hickman (1993). In the last column is the number of weather stations chosen for each species, followed by the mean number of years of data at those stations in parentheses.

\begin{tabular}{|c|c|c|c|c|}
\hline Taxon & Distribution & Elevation $(\mathrm{m})$ & Habit & $\begin{array}{c}\text { Stations } \\
\text { (years) }\end{array}$ \\
\hline \multicolumn{5}{|l|}{ Section Anogra } \\
\hline Oenothera arizonica & Sonoran Desert in sAZ, nwSonora & $210-600$ & $\mathrm{~A}^{1,4}$ & $9(81)$ \\
\hline O. californica ssp. californica & $\mathrm{sCA}, \mathrm{nBCN}$ & $300-2250$ & $\mathrm{P}^{1,11}$ & $12(53)$ \\
\hline O. californica ssp. eurekensis & $\begin{array}{l}\text { Endemic to the Eureka Dunes, nw of Death Valley, } \\
\text { CA }\end{array}$ & $\sim 1020$ & $\mathrm{P}^{1,2,11}$ & $1(45)$ \\
\hline O. deltoides ssp. howellii & Endemic to the Antioch dunes, CA & $\sim 30$ & $\mathrm{P}^{1,11}$ & $2(30)$ \\
\hline O. deltoides ssp. piperi & Great Basin Desert in wNV, neCA, seOR & $1200-1950$ & $\mathrm{~A}^{1,11}$ & $12(69)$ \\
\hline O. engelmannii & nwTX, wNM, and OK panhandle & $1500-1950$ & $A^{6,9,10}$ & $9(71)$ \\
\hline O. latifolia & $\mathrm{CO}, \mathrm{SD}, \mathrm{NE}, \mathrm{KS}, \mathrm{OK}, \mathrm{UT}, \mathrm{WY}, \mathrm{NM}$ & $1500-1950$ & $\mathrm{P}^{6,9}$ & $13(67)$ \\
\hline O. neomexicana & sNM, eAZ (+ Sedona, AZ) & $1800-2700$ & $\mathrm{P}^{6}$ & $11(58)$ \\
\hline O. nuttallii & $\begin{array}{l}\text { MT, WY, CO, ND, SD, NE, KS, MN, WI, Alberta, } \\
\text { Saskatchewan }\end{array}$ & $1050-2400$ & $\mathrm{P}^{9}$ & $13(64)$ \\
\hline O. pallida ssp. trichocalyx & WY, CO, UT & $1500-2400$ & $\mathrm{P} / \mathrm{B} / \mathrm{A}^{6}$ & $12(66)$ \\
\hline O. wigginsii & Coastal BCN & $0-30$ & $\mathrm{~A}^{1,3,5}$ & $5(46)$ \\
\hline \multicolumn{5}{|l|}{ Section Kleinia } \\
\hline O. albicaulis & $\begin{array}{l}\text { ND, SD, MT, WY, CO, NE, KS, OK, TX, NM, AZ, } \\
\text { UT, Sonora, Chihuahua }\end{array}$ & $1200-2250$ & $\mathrm{~A}^{7,9,10}$ & $16(82)$ \\
\hline O. coronopifolia & $\mathrm{SD}, \mathrm{NE}, \mathrm{KS}, \mathrm{WY}, \mathrm{CO}, \mathrm{UT}, \mathrm{NM}, \mathrm{AZ}$ & $1500-2400$ & $\mathrm{P}^{7,9}$ & $13(77)$ \\
\hline
\end{tabular}

* Not included in the study.

can be high if germination is cued to take advantage of both open space and moisture (i.e., germination occurs in response to rain) and if growth rates are high enough for plants to set seed before soil moisture disappears again. This droughtavoiding strategy is often cited to explain the success of annuals in deserts (Shreve 1951; Mulroy and Rundel 1977; Solbrig and Orians 1977; Ehleringer 1985; Crawley 1997; Smith et al. 1997; Dimmitt 2000). These ideas have persisted in the plant ecology literature (Solbrig et al. 1977; Ehleringer 1985; Barbour et al. 1987; Young and Augspurger 1991; Comstock and Ehleringer 1992; Crawley 1997; Dimmitt 2000; Gurevitch et al. 2002) and have been supported by a few comparative studies (Young 1984; van Groenendael and Slim 1988; Lesica and Shelly 1995) but have not been evaluated in a phylogenetic context.

We calculated phylogenetically independent contrasts of climate with respect to life history to evaluate whether more arid conditions and a higher coefficient of variation (CV) of precipitation are associated with the evolution of the annual habit. The plants in our study group of 21 taxa of Oenothera (evening primrose) all occur in relatively open, arid habitats: the loose, coarse-grained soils of dunes, sandhills, washes, or roadsides west of the 98th meridian in the United States (Klein 1970; see other references in Table 1). Because of their short generation times, we expect that the climate cur- rently occupied by these annuals and herbaceous perennials is not a relict of past distribution or climate.

We first consider the prediction that transitions to the annual habit should be associated with increased aridity and increased CV of precipitation on a yearly (annual) time scale, as suggested by Schaffer and Gadgil (1975). In addition, we examined seasonal components of these climate variables. We especially expect transitions to the annual habit to be associated with increased aridity and increased CV of precipitation in summer, because summer is the time of year that aridity is most extreme, and perennating plants must survive while annuals exist as seeds in our study group. Therefore, we evaluated how changes in seasonal components (summer vs. winter) of aridity and the CV of precipitation, as well as the variables contributing to aridity (potential evapotranspiration and precipitation), change with life history. Because temperature is a major factor driving potential evapotranspiration (PET), we also examined whether change in the average maximum temperature in summer versus winter was associated with change in life history. Very few studies have examined the evolution of the perennial versus annual habit in a phylogenetic context (Bena et al. 1998; Conti et al. 1999; Verboom et al. 2004), and none have explicitly related changes in habit to putative causal factors.

Phylogenetic uncertainty is a persistent problem when test- 
TABlE 2. Primer sequences used for polymerase chain reaction amplification (A) and sequencing (S).

\begin{tabular}{lllll}
\hline \hline \multicolumn{1}{c}{ Name } & Use & Direction & \multicolumn{1}{c}{ Sequence (5'-3') } & Reference \\
\hline ITS4 & A, S & reverse & TCC TCC GCT TAT TGA TAT GC & White et al. 1990 \\
ITS5HP & A, S & forward & GGA AGG AGA AGT CGT AAC AAG G & Hershkovitz and Zimmer 1996 \\
ITS2 & S & reverse & CGT AGC TAC TTC TTG CAT CG & White et al. 1990 \\
ITS3B & S & forward & GCA TCG ATG AAG AAC GTA GC & White et al. 1990 \\
C5.8S & S & forward & TGC GTT CAA AGA CTC GAT & Suh et al. 1993 \\
e & A, S & forward & GGT TCA AGT CCC TCT ATC CC & Taberlet et al. 1991 \\
f & A, S & reverse & ATT TGA ACT GGT GAC ACG AG & Taberlet et al. 1991 \\
trnH(GUG) & A, S & forward & ACG GGA ATT GAA CCC GCG CA & Demesure et al. 1995 \\
trnK(UUU) & A, S & reverse & CCG ACT AGT TCC GGG TTC GA & Demesure et al. 1995 \\
trnH & A, S & forward & GAA CGA CGG GAA TTG AAC & new \\
trnK & A, S & reverse & TTA TCT ACT CCA TCC GAC T & new \\
H400 & S & forward & TAC GCT CGT GCA TAA CTT CC & new \\
H400R & S & reverse & GGA AGT TAT GCA CGA GCA TC & new \\
KR400 & S & forward & GCT CAT AAG GAC CAC CGT TG & new \\
KR400R & S & reverse & GTT GCC ACC AGG AAT ACT CG & new \\
\hline
\end{tabular}

ing ideas in a historical framework (Harvey and Pagel 1991; Donoghue and Ackerly 1996; Huelsenbeck et al. 2000). We explicitly incorporated phylogenetic uncertainty into our estimation of change in climate with change in life history by calculating contrasts on a random sample $(n=1000)$ of the phylogenetic trees resulting from Bayesian analysis of our DNA sequence data. There is a straightforward null expectation for a single statistic from each tree: the mean contrast of climate with respect to habit should be zero. We evaluate the significance of our results by comparing the observed distribution of the mean contrast per tree to a similar distribution generated by randomizing the climate data.

\section{Materials And Methods}

\section{Study System}

Our study group includes the sections Anogra and Kleinia in the genus Oenothera (Onagraceae). This group of 21 taxa is well suited for the study of climate-driven evolution of the perennial versus annual habit: seven are annual, 12 are perennial (i.e., iteroparous), and two taxa vary in habit $(O$. deltoides ssp. cognata and $O$. pallida ssp. trichocalyx; see Table 1). We have included all but one in our study (O. pallida ssp. brevifolia, a perennial in the predominantly perennial species complex of $O$. pallida). These plants lack specialized means of storing water via succulence or thickened stems or rhizomes (Klein 1970). Phenology is more highly conserved than habit in this group: seedlings of both annuals and perennials recruit in the fall, winter, and spring, and flowering and fruiting occurs in the late spring or early summer. Existing taxonomic and phylogenetic information suggested that this is a monophyletic group with multiple changes in habit. The section Anogra, including the two taxa later placed in section Kleinia by Munz (1931), has long been recognized as a distinct entity; it was classified as a genus of its own by Spach (1835). More recently, the monophyly of Anogra + Kleinia was supported in a phylogenetic study focusing on the tribe Onagreae (Levin et al. 2004). Klein's (1970) hypothesis about the relationships among nine of the taxa in section Anogra, based on ecological, biogeographical, cytogenetic, and artificial hybridization data, suggested that at least three changes in habit had occurred.
We included 10 outgroup taxa in our study in addition to the 20 ingroup taxa. These were species from seven other sections of the genus Oenothera, including species from the four sections most closely related to sections Anogra and Kleinia, according to the study of Levin et al. (2004): $O$. primiveris from section Eremia; O. xylocarpa from section Contortae; O. tubifera from section Ravenia; and O. elata ssp. hookeri, O. stubbei, O. organensis, and O. magellanica from section Oenothera. Three other sections represented in our outgroup are Lauvaxia (by $O$. flava ssp. taraxacoides), Xylopleurum (by O. speciosa), and Hartmannia (by O. tetraptera).

\section{DNA Sequence Data}

Total genomic DNA was extracted from the sources shown in Supplementary Table 1 available online only (at http:// dx.doi.org/10.1554/04-708.1.s1), using the extraction protocol of Taylor and Powell (1982) or a modified CTAB protocol (Doyle and Doyle 1987). One nuclear and two plastid noncoding regions were sampled for this study: the internal transcribed spacer (ITS) of the nuclear ribosomal RNA cistron (Baldwin 1992; Baldwin et al. 1995) and the plastid intergenic spacers between trnL-trnF (Taberlet et al. 1991) and trnH-trnK (Demesure et al. 1995). Primers used for polymerase chain reaction (PCR) amplification and sequencing are shown in Table 2. Standard PCR protocols were used to amplify these regions, and the PCR products were cleaned with $\mathrm{PEG} / \mathrm{NaCl}$ precipitation (Kusakawa et al. 1990). Cycle sequencing of the PCR products used ABI Big Dye chemistry (Applied Biosystems, Foster City, CA) and all reactions were run on an ABI 377 automated sequencer.

Sequence fragments were edited and contiguous sequences generated using Sequencher version 3.1 (Gene Codes Corp., Ann Arbor, MI). We used ClustalX (ver. 1.8; Thompson et al. 1997) to align the sequences. This alignment employed the multiple sequences alignment mode, using the factory settings, with the exception of the gap opening cost set at 15. Each gene region was aligned separately, then the aligned sequences were concatenated for subsequent analyses. 


\section{Phylogenetic Analyses}

Phylogenetic analyses were performed on the aligned sequences using MrBayes (ver. 2.01; Huelsenbeck and Ronquist 2001). We used the general time reversible model of nucleotide evolution, with site-specific rate heterogeneity estimated by the gamma distribution (GTR $+\Gamma$; Yang 1993, 1994), and the priors set to the defaults in MrBayes. We ran the Markov-chain Monte Carlo simulation for 1 million generations, sampling every 50th generation. We saved the sampled trees after the log-likelihood score had converged for subsequent analyses (i.e., trees from the posterior distribution).

\section{Climate Data}

We quantified climatic variables with long-term weather records from stations throughout the range of each taxon, using herbarium specimens to identify stations near collection localities. We used range maps created by Warren Wagner at the Smithsonian Institution, which were based on specimens in the U.S. National Herbarium. To some of these maps, we added localities from loan material from another six herbaria: Rancho Santa Ana Botanic Garden, University of Nevada at Las Vegas, University of California at San Diego, University of New Mexico, University of California at Berkeley, and University of Arizona. We then added weather stations to the range maps, identifying stations that were closest to plant localities geographically and in elevation, and those with the longest record of weather. Our final choices were spatially stratified with respect to the range of each taxon. The total number of stations chosen per taxon ranged from one (dune endemics) to 16 (see Table 1; Supplementary Table 2 available online only at http://dx.doi.org/ 10.1554/04-708.1.s1).

Summary statistics from each station's period of record were obtained from Web pages maintained by the Western Regional Climate Center (WRCC) or High Plains Regional Climate Center of the National Oceanic and Atmospheric Administration or by request from the WRCC. Details of how the statistics are calculated can be found on the Web pages (see http://www.wrcc.dri.edu/summary/). One species, $O$. wigginsii, is found only in Baja California Norte, Mexico. We obtained summary statistics for this species from three sources: Miranda et al. (1991), Quintas (2000), and technical report number BOO.00.R02.07.4.-02.439, from the Comisión Nacional del Agua.

The historical summary statistics that we compiled were mean high and low temperatures, mean precipitation, and the $\mathrm{CV}$ of precipitation for each month (January-December), as well as mean annual precipitation and the $\mathrm{CV}$ of annual precipitation. We also gathered mean daily temperatures to calculate potential evapotranspiration (PET), a measure of the drying power at a particular location over any given time period. In theory, PET is "the amount of water ... transpired by a short green crop, completely shading the ground, of uniform height and never short of water', (Penman 1956). We used the Hargreaves equation to estimate PET (Hargreaves and Samani 1982; see Online Appendix available at http://dx.doi.org/10.1554/04-708.1.s2), which, as we implemented it, relies entirely on temperature and latitude data.
PET was estimated on a daily basis, then summed to obtain monthly and yearly values for each station. Using the PET and precipitation data, we calculated two indices of aridity. The first, attributed to Budyko (1974), is PET divided by precipitation. This index emphasizes the kind of aridity generated by drought. If precipitation is very low, the denominator of the index is small and aridity is estimated to be very high. Those cases in our dataset where average precipitation was zero were replaced with the smallest amount of precipitation observed at another weather station in that time period. These estimates of aridity were log-transformed before any subsequent manipulations. The second index of aridity, the difference between PET and precipitation, emphasizes the kind of aridity generated by high temperatures. These two indices measure the relative and absolute differences between potential water losses and actual water gains, respectively.

Species-level values for each climate variable were calculated by averaging across weather stations within species. To examine seasonal components of the $\mathrm{CV}$ of precipitation (summer vs. winter), we found the mean of CVs of precipitation in summer months (June-August) versus winter months (October-March). Winter high temperature was measured by the mean of mean high temperatures per month for the period including October through March. Because summer occurs at different times at different latitudes, we used the mean high temperature in the warmest month for summer high temperature. We found the highest mean high for each weather station, then found the mean across stations within species, to deal with latitudinal diversity in peak temperature within species.

\section{Changes in Life History and Climate: Phylogenetically Independent Contrasts}

We used comparative analysis by independent contrasts (CAIC; Purvis and Rambaut 1995; ver. 2.7.1, modified by N. Isaac) to calculate phylogenetically independent contrasts (PICs) of climate variables with respect to habit. The Brunch algorithm in CAIC calculates independent contrasts for combinations of categorical and continuous data. We made habit a dichotomous variable by grouping the taxa that are capable of more than one habit $(O$. deltoides ssp. cognata and $O$. pallida ssp. trichocalyx) with the perennials. As such, our habit categories are best described as "potentially perennial", versus "obligately annual.', We assigned values for habit (obligately annual $=1$, potentially perennial $=0$ ) so that contrasts were always calculated by subtracting the climate value for a perennial from an annual. As a consequence, positive contrasts indicate that change to the annual habit is associated with an increase in the climate variable and negative contrasts indicate that change to the annual habit is associated with a decrease in the climate variable.

To explicitly incorporate phylogenetic uncertainty into our test, we calculated contrasts on a random sample $(n=1000)$ of trees from the posterior distribution of the Bayesian analysis. The null expectation is that the mean of the contrasts on any single tree is zero. A sign test or one-sample $t$-test is typically used to evaluate whether contrasts are significantly different from zero. Because of the small number of contrasts per tree in our study (typically five; see Results), we have a 
TABle 3. Descriptive statistics of climate where the taxa in sections Anogra and Kleinia (Oenothera, Onagraceae) are found and of contrasts of these climate variables with respect to life history (obligately annual vs. potentially perennial). For each climate variable, the mean (range) for all taxa is reported, as well as the mean and standard deviation for the perennial versus annual taxa. PET, potential evapotranspiration; P, precipitation; CV, coefficient of variation. Summer includes June through August; winter includes October through March. Contrast statistics include the percentage of the distribution of random average contrasts that falls below the mean of the distribution of observed average contrasts, the corresponding $P$-value describing the association between change in climate and change in habit, and the number of trees on which the average contrast is positive (corresponding to Figs. 2-6).

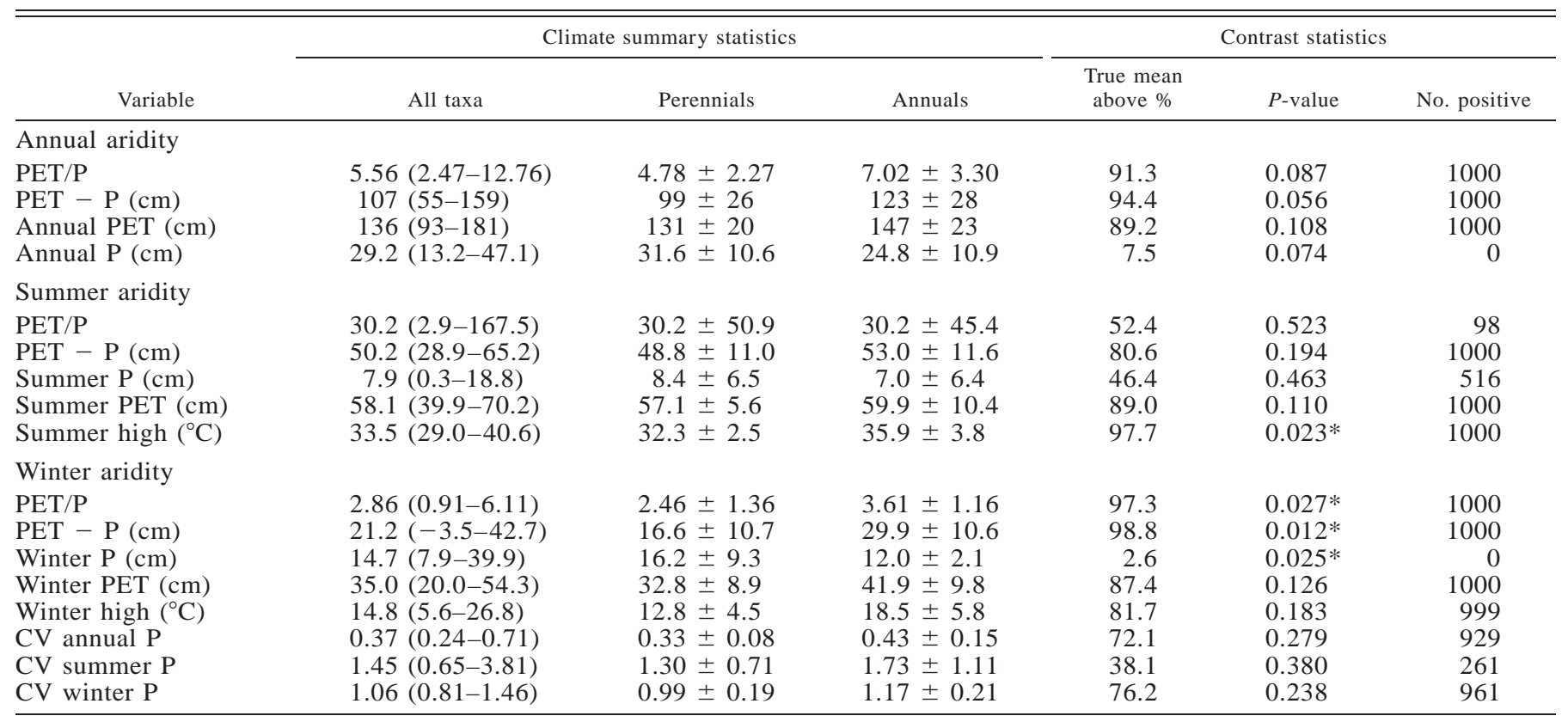

lack of statistical power, so we know a priori that such tests are likely to give nonsignificant results. Instead, we compare the distribution of the mean contrast per tree, calculated on the 1000 Bayesian trees, to the distribution of the mean contrast per tree, calculated on the same trees but with the climate data randomized in the ingroup (observed vs. random mean contrasts, respectively). The climate data were randomized by sampling the actual values without replacement and assigning them to the ingroup taxa. This randomization procedure generates a distribution of the mean contrast per tree that can be expected under chance association between the habit and climate data on the phylogenies. Hence we use this as a null distribution against which we compare the distribution of observed mean contrasts. We consider a pattern of association between change in climate and change in life history to be significant if the mean of the observed mean contrasts is more extreme than $95 \%$ of the distribution of the random mean contrasts. We use a one-tailed test because we have specific directions in which we expect climate to change with the evolution of the annual habit (i.e., increased aridity, PET, temperature, CV of precipitation, and decreased precipitation). We calculated contrasts between habit and 17 climate variables (i.e., 17 tests). Bonferroni adjustment of the alpha level is a procedure used to control against the chance of making even one Type I error (falsely declaring a significant effect) among multiple tests. Given an initial alpha level of 0.05 and 17 tests, one would require a $P$-value to be less than 0.003 to be considered significant. This correction has been described as conservative because it comes at the direct cost of making Type II errors (falsely declaring no effect;
Moran 2003; Verhoeven et al. 2005). Balancing the chances of making Type I and Type II errors in multiple tests is an active area of discussion and development (Garcia 2004; Verhoeven et al. 2005). We proceed by reporting significance in terms of the unadjusted alpha level and subsequently revisit the issue of multiple tests.

\section{RESULTS \\ DNA and Phylogenies}

Our sequence data set included 2888 aligned characters, compiled from ITS (701 bp), trnL-trnF (458 bp), and trnHtrnK (1729 bp). Of these 2888 sites, 2533 were constant, 221 were variable but not parsimony informative, and 134 (4.6\%) were parsimony informative. GenBank accession numbers are reported in the Supplementary Table 1 (available online only). In the Markov-chain Monte Carlo simulation, the loglikelihood scores converged after about 60,000 generations. Sections Anogra + Kleinia were recovered as a monophyletic group in all of the trees sampled from the posterior distribution of the Bayesian analysis (Fig. 1). CAIC found five, four, or three contrasts in habit on $70 \%, 29 \%$, and $1 \%$ of the 1000 trees selected for further analysis, respectively. We do not focus on the specific location and direction of evolutionary transitions in habit on the phylogenies in this study, though we note that transitions in both directions may have occurred in the history of this group (Fig. 1).

\section{Climate Data}

Among the taxa in sections Anogra and Kleinia, annual aridity measured by the ratio of PET and precipitation ranged 

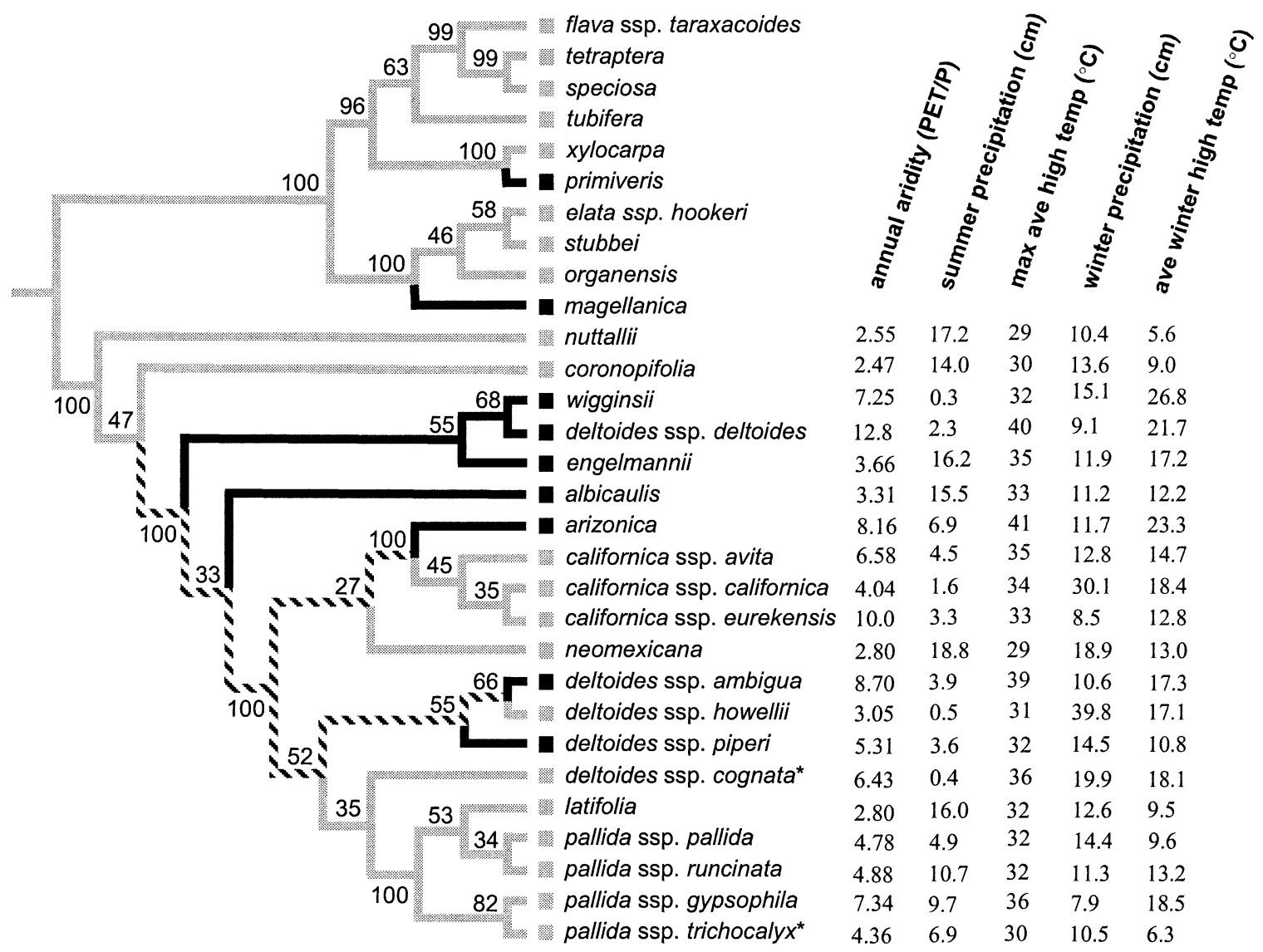

FIG. 1. Phylogenetic hypothesis for several species in the genus Oenothera (Onagraceae). This cladogram was generated using the "sumt contype=allcompat" command in MrBayes, which leads to a fully resolved version of the 50\% majority rule consensus tree, with the most frequent resolution shown for those nodes with less than $50 \%$ support. Numbers indicate the frequency that the clade is encountered in the sample from the posterior distribution. Life history is mapped on using parsimony, with the perennial habit in gray and the annual habit in black. Branches that are ambiguous with respect to life history are hatched. The two taxa that are variable in habit are noted with an asterisk. Data for five climate variables are shown for the ingroup taxa, which include the members of the sections Anogra and Kleinia.

from 2.5 to 12.8 , with a mean of 5.6 (Table 3 ), demonstrating that all species occur in areas that would be considered semiarid to arid (Ponce et al. 2000; Arora 2002). Mean summer aridity was more extreme than mean winter aridity (30.2 vs. 2.9 , respectively), as was variation in summer aridity (2.9167.5 vs. 0.9-6.1, respectively; Table 3). The same patterns were true for aridity measured by the difference between PET and precipitation (Table 3). However, the five taxa with the most extreme summer aridity differed between the two measures. Measured by the ratio of PET and precipitation, they were $O$. deltoides ssp. cognata, $O$. wigginsii, $O$. deltoides ssp. howellii, O. californica ssp. californica, and $O$. deltoides ssp. deltoides, which are variable in habit, annual, perennial, perennial, and annual, respectively. Four of these five (not $O$. wigginsii) are found in California, where the Mediterranean climate has a pronounced summer drought. The Vizcaino subdivision of the Sonoran Desert, where $O$. wigginsii is found, is characterized by very little rainfall but frequent fog (Dimmit 2000). Measured by the difference between PET and precipitation, the five taxa with the most extreme values for summer aridity were $O$. deltoides ssp. deltoides, $O$. deltoides ssp. ambigua, O. deltoides ssp. cognata, O. arizonica, and $O$. californica ssp. avita, which are annual, annual, var- iable in habit, annual, and perennial, respectively. These species, especially $O$. deltoides ssp. deltoides, $O$. deltoides ssp. ambigua, and $O$. arizonica, are found at low elevations and low latitudes, where temperatures are high. The $\mathrm{CV}$ of annual precipitation varied from 0.24 to 0.71 among species (Table 3). Mean winter high temperature (October and March) ranged from $6^{\circ} \mathrm{C}$ to $27^{\circ} \mathrm{C}$ among species, while the mean high temperature in the warmest month ranged from $29^{\circ} \mathrm{C}$ to $41^{\circ} \mathrm{C}$ (Table 3).

\section{Changes in Life History and Climate}

We have chosen to discuss the results in terms of climatic changes associated with evolutionary transitions to the annual habit, even though the phylogeny in Figure 1 illustrates that changes may have occurred in both directions (and hence, opposite trends in climate change may have occurred with evolutionary transitions from the annual to the perennial habit). This choice is made for brevity and for clarity with respect to the predictions set forth in the introduction. As predicted, transitions to the annual habit were associated with increased annual aridity, whether measured in terms of the relative or absolute difference between PET and precipitation. However, 

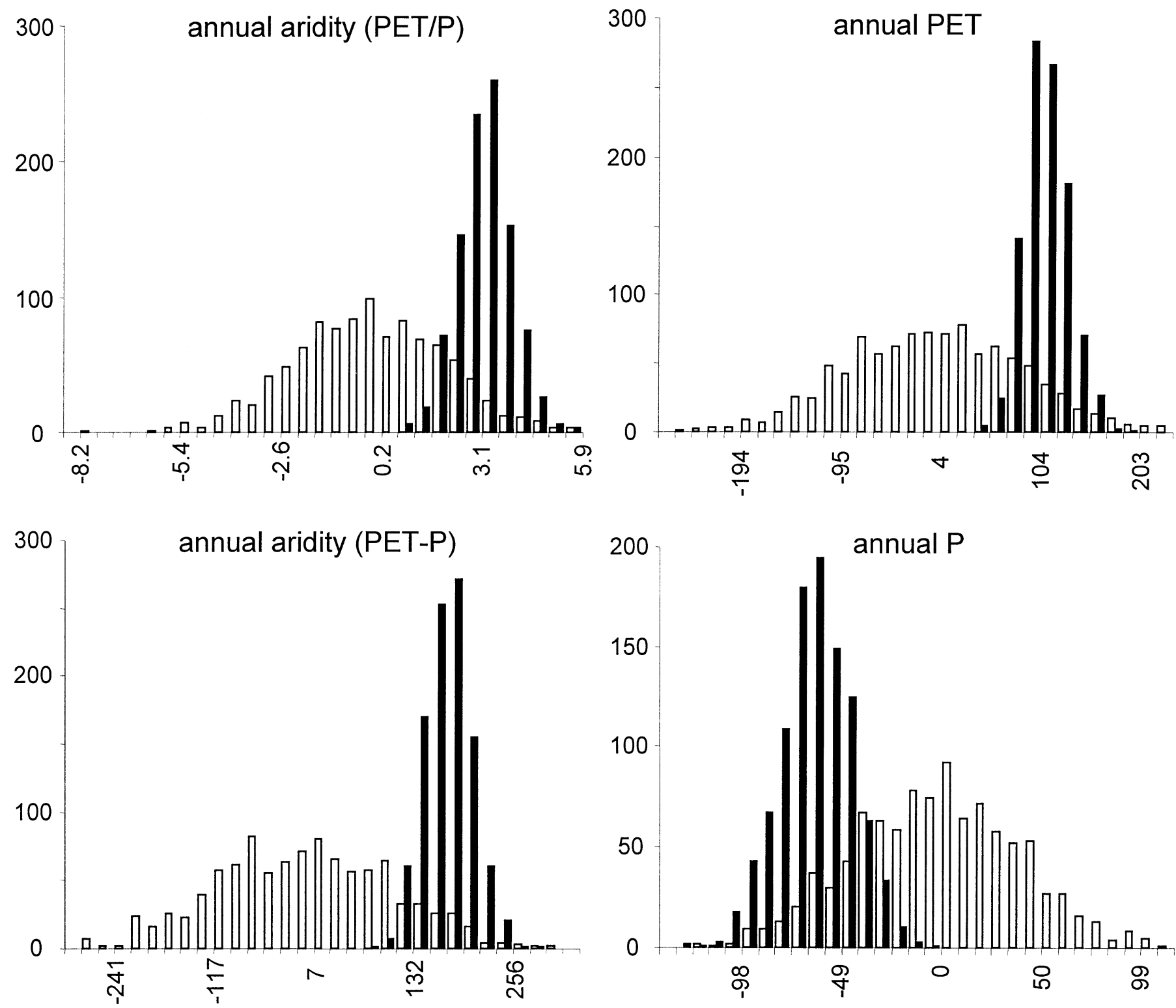

FIG. 2. Frequency histograms of the average contrast per tree, where contrasts were calculated on 1000 Bayesian trees. Solid bars are the observed average contrasts, while open bars are average contrasts generated by a randomization procedure (see Materials and Methods). Each climate variable was contrasted with respect to habit (annual vs. perennial). PET, potential evapotranspiration; P, precipitation.

this was a trend rather than a significant pattern $(P>0.05$; Table 3, Fig. 2). Both measures of annual aridity give the same pattern because transitions to the annual habit were (nonsignificantly) associated with increased annual PET and decreased annual precipitation (Table 3, Fig. 2). On a yearly time scale increases in both causes of aridity, drought and heat, were (nonsignificantly) associated with transitions to the annual habit.

Counter to our expectation, transitions to the annual habit were not consistently associated with increased aridity in summer, the season of most extreme aridity. Measured by the ratio of PET and precipitation, transitions to the annual habit were actually associated with decreased summer aridity on about $90 \%$ of the trees (Table 3, Fig. 3). If May is included in the summer months, this pattern becomes weaker: about
$67 \%$ of trees indicate that transitions to the annual habit were associated with decreased summer aridity (data not shown). In contrast, transitions to the annual habit were associated with increased summer aridity on all 1000 trees sampled from the posterior distribution, when aridity is measured by the difference between PET and precipitation, though this trend is not significantly different from the null pattern $(P=0.194$; Table 3, Fig. 3). We obtained different results from different indices of aridity because of patterns in the lower-level variables, PET and precipitation. Transitions to the annual habit were associated with decreased summer precipitation on just half the trees, so the distribution of observed average contrasts is centered on the null value of zero (Table 3, Fig. 3). However, transitions to the annual habit were consistently (but not significantly) associated with increased summer PET 

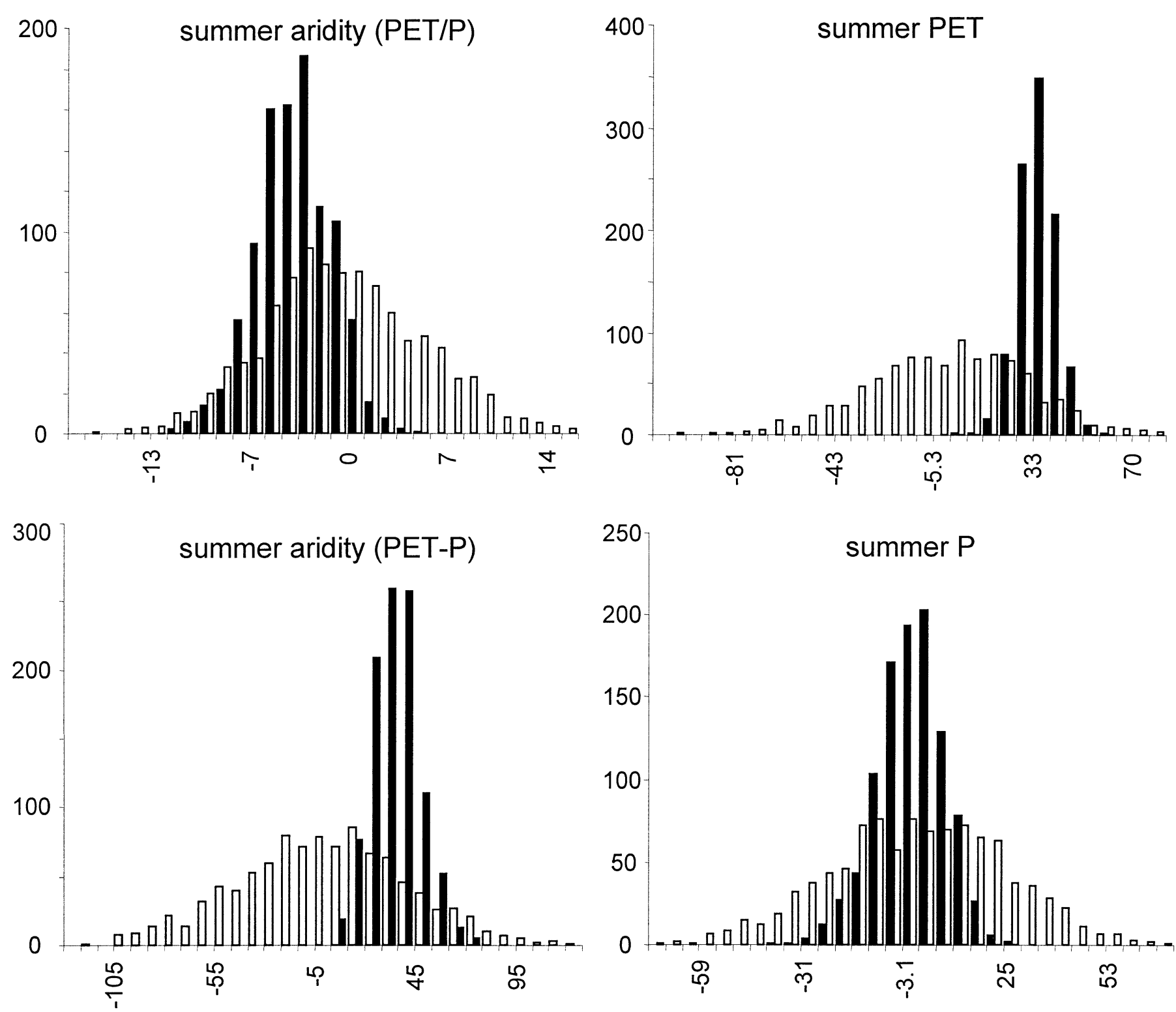

FIG. 3. Frequency histograms of the average contrast per tree, as in Figure 2. Solid bars are the observed average contrasts, while open bars are average contrasts generated by a randomization procedure (see Materials and Methods). Each climate variable was contrasted with respect to habit (annual vs. perennial). PET, potential evapotranspiration; P, precipitation. Summer includes the months June through August.

$(P=0.110$; Table 3, Fig. 3). The ratio of PET and precipitation is sensitive to small values of precipitation, and there are several perennials in our study group that grow in places with little summer precipitation (e.g., O. deltoides ssp. howellii, O. californica ssp. californica, and O. californica ssp. eurekensis). Hence the ratio of PET and precipitation does not show an increase in summer aridity with change in habit, while the difference between PET and precipitation reflects the trend toward increased PET associated with transitions to the annual habit. Increased summer temperatures were significantly associated with transitions to the annual habit $(P$ $=0.023$; Table 3, Fig. 4), driving the trend toward increased summer PET. Among the two causes of aridity, transitions to the annual habit were associated with increased summer heat but not increased summer drought.
In contrast, transitions to the annual habit were consistently and significantly associated with increased winter aridity, whether aridity was measured by the relative or absolute difference between PET and precipitation $(P=0.027$ and $P$ $=0.012$, respectively; Table 3 , Fig. 5). This pattern was insensitive to the type of aridity index because both decreased precipitation $(P=0.025)$ and increased PET $(P=0.126)$ in the winter months were associated with transitions to the annual habit (Table 3, Fig. 5). There was a trend for transitions to the annual habit to be associated with increased mean high temperatures in winter months (contributing to the trend toward increased winter PET), but this pattern is not significant ( $P=0.183$; Table 3 , Fig. 4).

As predicted, transitions to the annual habit were associated with increased CV of annual precipitation (on $93 \%$ of 

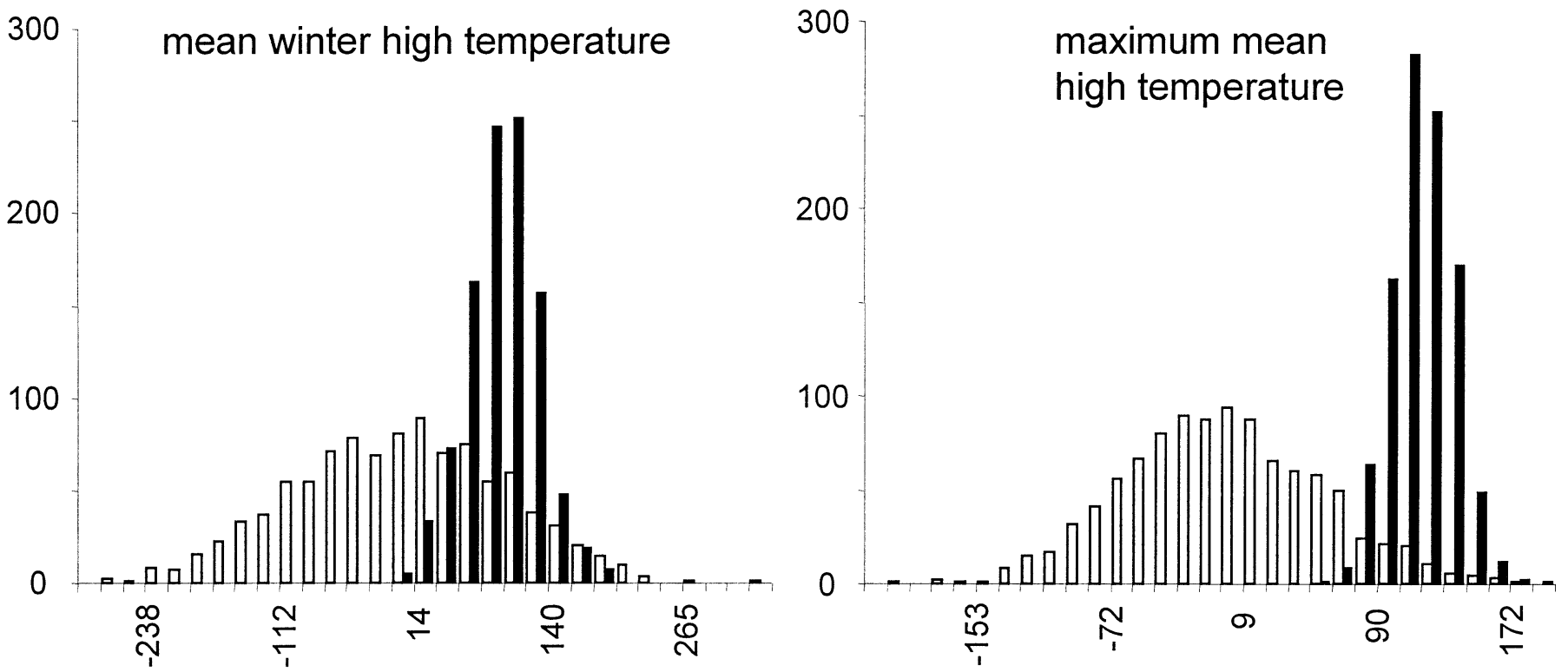

FIG. 4. Frequency histograms of the average contrast per tree, as in Figure 2. Solid bars are the observed average contrasts, while open bars are average contrasts generated by a randomization procedure (see Materials and Methods). Each climate variable was contrasted with respect to habit (annual vs. perennial). Winter includes the months October through March.

the trees), but this trend did not significantly distinguish itself from the null expectation $(P=0.279$; Table 3, Fig. 6). The pattern in contrasts of the $\mathrm{CV}$ of precipitation in summer and winter months is also in the predicted direction, but is nonsignificant $(P=0.380$ and $P=0.238$, respectively; Table 3, Fig. 6).

Among 17 tests, four indicate a significant effect at the unadjusted alpha level of 0.05 . The concern is that, among 17 tests, the probability of finding one or more significant result by chance is high $\left(1-[1-\alpha]^{17}=0.582\right)$, hence the motivation for a Bonferroni correction (Moran 2003). After applying either a classical or sequential Bonferroni method (or the false-discovery-rate method of Verhoeven et al. 2005), none of the climate effects would be considered significant. The global hypothesis of no climate effects on life history cannot be rejected, after applying methods that emphasize control of Type I error. At the same time, the probability that all four significant climate effects are false positives is quite small ( $P=0.008$; using the Bernoulli model in Moran 2003). And the truncated product method of Zaykin et al. (2002; suggested by Neuhauser 2004) indicates that it is highly likely that at least one of those four effects is not a false positive (TPM $P=0.007$ ). With these considerations in mind, we interpret our results with caution.

\section{DiscusSION}

\section{Associations between Climate and Life History}

Our analysis identified a set of climate variables, among which at least some are likely to have changed along with the evolution of habit. Transitions to the annual habit were associated with increased annual aridity, as suggested by Schaffer and Gadgil (1975), though this trend was not significant compared to randomly generated contrasts on the same set of phylogenetic trees $(P>0.05)$. The prediction that transitions to the annual habit should be associated with an increased $\mathrm{CV}$ of annual precipitation was not supported by the data.

While ours is the first study to use this combination of phylogenetic, climatic, and life-history data, other comparative studies have evaluated the idea that the annual habit, or semelparous strategy, is found under drier or less-productive conditions. Many studies support this idea (Young 1984; van Groenendael and Slim 1988; Lesica and Shelly 1995; Verboom et al. 2004; see also references in Young and Augspurger 1991). In a remarkable paper, Smith and Charnov (2001) suggested that adaptations to the harsh climate of Death Valley, California, favored a switch from iteroparity to semelparity in a small woodrat (only the second known occurrence of semelparity in mammals). Other studies have associated external sources of mortality other than harsh climatic conditions, such as predation or disturbance, with semelparity or annuality or shorter life span (Law et al. 1977; Boutin and Harper 1991; Oyama 1994; Schneider and Lubin 1997; Hautekeete et al. 2002). However, some comparative studies have provided counter-examples to these trends in life-history variation with environment (Wilbur 1976; Hickman 1977). Robichaux et al. (1990) documented the coexistence of semelparous and iteroparous members of the silversword alliance at dry sites in Hawaii.

This is the first phylogenetic study to examine the pattern of life history and climate on a seasonal basis, that is, on a scale of temporal resolution finer than a year. This is important because life-history theory suggests that which reproductive strategy is favored depends on the relative force of mortality (or variation in mortality) on seedlings versus adults (Charnov and Schaffer 1973; Schaffer 1974; Stearns 1992; Rees 1994; Tuljapurkar and Wiener 2000). Schaffer and Gadgil's (1975) predictions were based on the notion that harsh conditions, in the form of extreme aridity and 

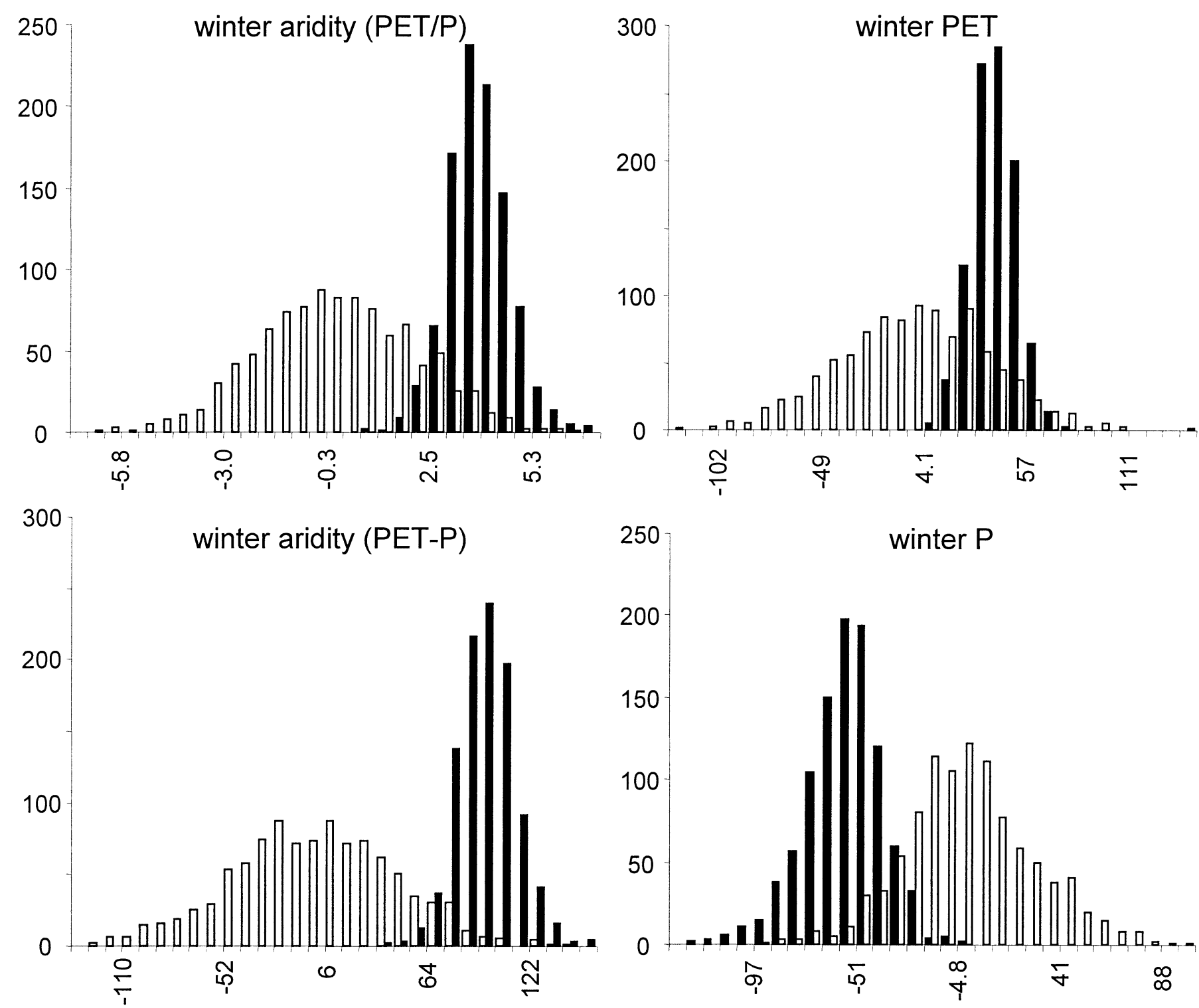

FIG. 5. Frequency histograms of the average contrast per tree, as in Figure 2. Solid bars are the observed average contrasts, while open bars are average contrasts generated by a randomization procedure (see Materials and Methods). Each climate variable was contrasted with respect to habit (annual vs. perennial). PET potential evapotranspiration; P, precipitation. Winter includes the months October through March.

droughts of variable lengths, should make it more difficult for perennating organs to survive, lowering adult survival and favoring the annual habit in the manner suggested by demographic models (Charnov and Schaffer 1973; Young and Augspurger 1991; Charlesworth 1994; Roff 2002). By examining summer and winter climate patterns separately, we were able to focus on times of the year when one life-history stage should be more affected than another. We expected transitions to the annual habit to be associated with increased aridity and $\mathrm{CV}$ of precipitation in summer months, when aridity is most extreme and when perennials must survive but annuals exist as dormant seeds. Transitions to the annual habit were associated with increases in one aspect of aridity in summer, heat, but not the other aspect of aridity, drought. Transitions to the annual habit were not associated with change in summer precipitation, nor were they associated with change in the $\mathrm{CV}$ of summer precipitation. It seems that evolution life history (perennial vs. annual) in this group is not sensitive to summer drought but is sensitive to extreme summer heat. The inference regarding summer heat should be viewed as weak, in the sense that this study is correlative and uncontrolled at the same time that multiple tests raise the risk of false detection of effects. Nonetheless, it seems likely that drought-induced dormancy plays an important role in allowing perennials like the three subspecies of $O$. californica, $O$. deltoides ssp. howellii, and $O$. deltoides ssp. cognata, which all occur in the summer-drought Mediterranean climate of California, to persist as perennial.

A second reason we did not find transitions to the annual habit to be associated with decreased summer precipitation 

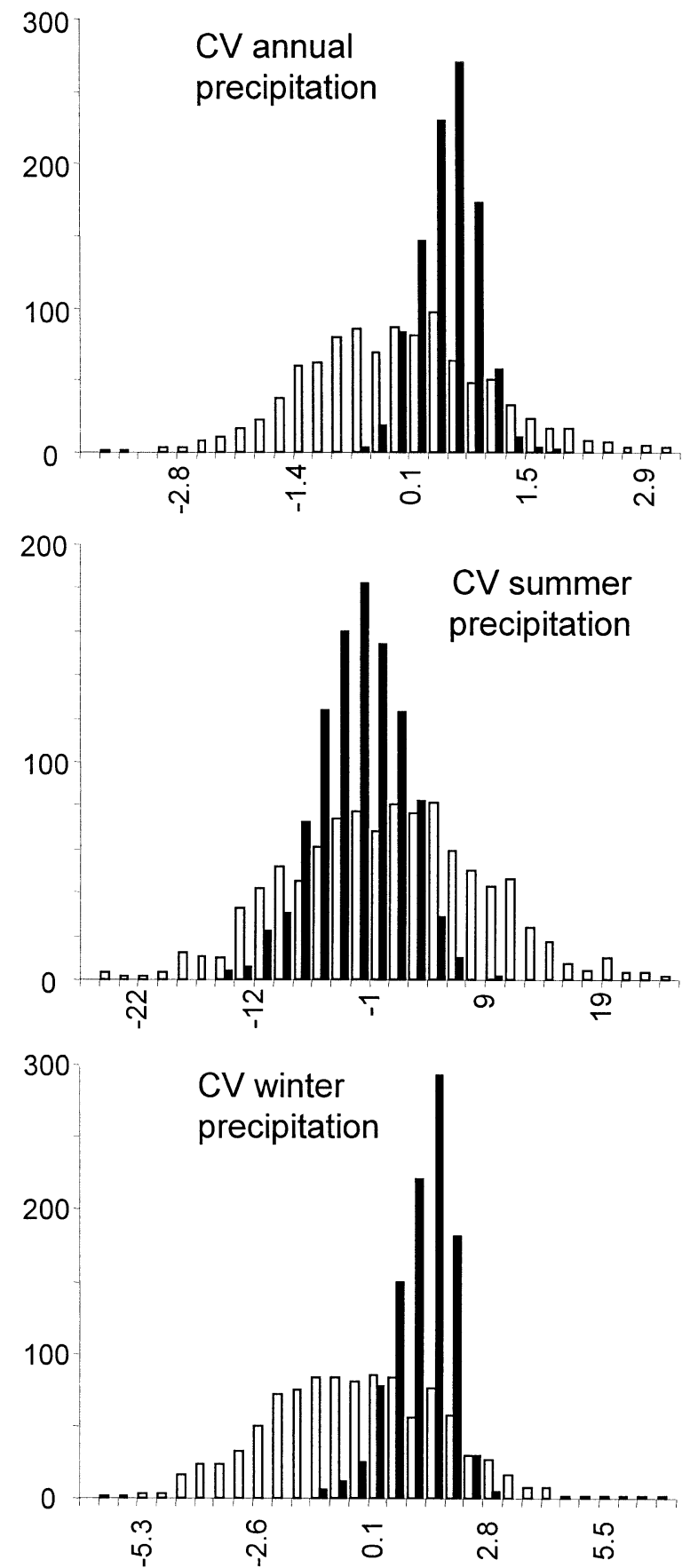

FIG. 6. Frequency histograms of the average contrast per tree, as in Figure 2. Solid bars are the observed average contrasts, while open bars are average contrasts generated by a randomization procedure (see Materials and Methods). Each climate variable was contrasted with respect to habit (annual vs. perennial). CV, coefficient of variation.

was the occurrence of some annuals in places with significant summer precipitation. Examples include $O$. engelmannii and O. albicaulis. With summer precipitation available, one might expect these plants to survive after the first spring and continue to reproduce (and be perennial rather than annual). Many plants that are physiologically active in the summer, especially summer annuals and warm-season grasses, have
C4 photosynthesis rather than C3 photosynthesis (Mulroy and Rundel 1977; Solbrig and Orians 1977; Solbrig et al. 1977; Ehleringer 1985; Ehleringer and Monson 1993; Gurevitch et al. 2002). C4 photosynthesis is a variant process that excels under high light and temperature conditions and has higher water-use efficiency (Lambers et al. 1998; Gurevitch et al. 2002). The perennial habit might persist in places with summer rain, and hence we might better see the predicted relationship between aridity (measured by PET/precipitation) and annuality in summer, if these plants had the greater physiological capacity for taking advantage of summer precipitation conferred by $\mathrm{C} 4$ photosynthesis. Alternatively, we might see the evolution of summer annuals in our study group. C4 photosynthesis is not known in the genus Oenothera, nor in the Onagraceae. In general, it may be difficult to be adapted to physiological activity in both winter and summer, and the historical physiology and phenology of this group (C3 photosynthesis and winter recruitment) may act as an evolutionary constraint.

Rather than finding transitions to the annual habit to be associated with increased summer aridity or increased summer drought, we found that they may have been associated with these same changes in climate in winter (OctoberMarch). Transitions to the annual habit were significantly associated with increased winter aridity (according to unadjusted $P$-values), whether measured by the ratio or the difference between PET and precipitation. Both increased PET and increased drought in winter were associated with transitions to the annual habit, the latter significantly so (based on unadjusted $P$-values). The idea that change in life history from perennial to annual should occur in response to increased aridity and drought during the season of seedling recruitment has at least two explanations. As delineated in the introduction, increased aridity and drought make it difficult for other plants to survive, generating the open space needed for seedling survival to be high, favoring the annual habit (Schaffer and Gadgil 1975; Silvertown and Charlesworth 2001). But increased aridity and drought in summer were not associated with transitions to the annual habit in our study group. It is not clear why the degree of interspecific competition experienced by plants in our study group should be shaped by increased aridity and drought in winter but not in summer. One would especially expect the percentage cover of permanent vegetation to respond to these climatic changes in summer, when aridity is most extreme. Furthermore, all of the plants in our study group are found in relatively open habitats: places like dunes, washes, sandhills, and roadsides, where vegetation is sparse either because of disturbance or because of special soil characteristics (references in Table 1).

A second explanation is specific to increased aridity via increased drought in winter. Rain events during the season of germination and seedling growth represent windows of opportunity for seedling recruitment and reproductive success. With less average precipitation during this season, these windows of opportunity become less numerous, shorter in duration, or both. Pulses of soil moisture of shorter duration may especially favor the drought-avoiding strategy of an annual over the more long-lived strategy of a perennial. Perennials must continue to survive after soil moisture condi- 
tions deteriorate, either as seedlings or if they reproduce at the same time as annuals, as adults. This explanation is consistent with recent research on the role of the timing, duration, or depth of soil moisture pulses in favoring different plant growth forms in arid environments (Schwinning and Ehleringer 2001; Schenk and Jackson 2002). The idea that more detailed aspects of soil moisture patterns or overall season length may influence life-history evolution can be evaluated as the ideas of Schaffer and Gadgil (1975) and Charnov and Schaffer (1973) have been evaluated here. Careful thinking about other variables that may be correlated with the climates variables highlighted by this study, complimented by experimental study, will provide a more solid basis for inference about the causes of life-history evolution and diversification in this and other herbaceous plant groups. The ideas are general enough to apply to other groups as well.

For example, temperature is a variable that may modify or interact with the effect of season length on different life histories. It has been observed that annuals are not prevalent in cold deserts (Comstock and Ehleringer 1992; Gurevitch et al. 2002), or in cold, open environments like arctic or alpine biomes (Raunkiaer 1934; Daubenmire 1968; Dimmitt 2000). Warm temperatures allow plants to grow rapidly, which may be critical to successfully produce a new generation of seeds within a short period of soil moisture availability (Comstock and Ehleringer 1992; Evans 2003). There was a trend for transitions to the annual habit to be associated with increased winter temperatures in our study group, though this pattern was not significant compared to the null. Still, the idea deserves further investigation. A refined understanding of how different life histories are favored by climate will be useful in a world facing climate change.

Our study implies that evolution from the perennial to the annual habit occurs in response to increasingly arid environmental conditions, but it illustrates that several factors may modify this response. The physiological capabilities of a particular group may cause life history to evolve in response to some aspects of aridity but not others. In this group of plants, we infer that evolution from the perennial to the annual habit has occurred in response to increased heat but not increased drought during the season of most extreme aridity, probably because of the ability of perennials to enter drought-induced dormancy. At the same time, a historical lack of other physiological capabilities may constrain life-history evolution in response to resource availability (e.g., summer precipitation where some annuals in our study group are found). While on a larger scale it seems clear that hot, dry environmental conditions reduce plant cover and the interspecific competition that suppresses seedling recruitment (e.g., in a forest compared to a desert), the results from our study group were less consistent with a role for plant cover and more consistent with a role for changes in the patterns of precipitation within the season of seedling recruitment in favoring the perennial versus annual strategy. It may be that multiple factors (extreme summer heat combined with decreased winter precipitation) conspired to favor the evolution of the annual habit over the evolutionary history of our study group.

\section{ACKNOWLEDGMENTS}

This research would not have been possible without the generous assistance of R. Raguso, W. Wagner, N. Isaac, K.
Sytsma, R. Levin, P. Jenkins, and M. Kaplan. K. Holsinger, D. Maddison, G. McPherson, and M. S. Singer provided valuable feedback and advice. This manuscript benefited from the comments of D. Ackerly, M. Johnston, O. Pellmyr, and two anonymous reviewers. The research was supported by the National Science Foundation through DEB-0105145 to DLV and MEKE, through an RTG in the Analysis of Biological Diversification administered by the Department of Ecology and Evolutionary Biology (EEB) at the University of Arizona, and through an IGERT administered by the Program in Applied Mathematics at the University of Arizona. We also thank EEB and the American Society for Plant Taxonomists for their financial support. This research represents a partial fulfillment of the requirements for the degree of Doctor of Philosophy in Ecology and Evolutionary Biology at the University of Arizona. This paper is dedicated to Bert G. Brehm, who inspired MEKE's study of plant life-history evolution.

\section{Literature Cited}

Arora, V. K. 2002. The use of the aridity index to assess climate change effect on annual runoff. J. Hydrol. 265:164-177.

Baldwin, B. G. 1992. Phylogenetic utility of the internal transcribed spacers of nuclear ribosomal DNA in plants: an example from the Compositae. Mol. Phylogenet. Evol. 1:3-16.

Baldwin, B. G., M. J. Sanderson, J. M. Porter, M. F. Wojciechowski, S. S. Campbell, and M. J. Donoghue. 1995. The ITS region of nuclear ribosomal DNA: a valuable source of evidence on angiosperm phylogeny. Ann. Mo. Bot. Gard. 82:247-277.

Barbour, M. J., J. H. Burk, and W. D. Pitts. 1987. Terrestrial plant ecology. 2nd ed. Benjamin Cummings, Inc., Menlo Park, CA.

Bell, G. 1976. On breeding more than once. Am. Nat. 110:57-77.

Bena, G., B. Lejeune, J.-M. Prosperi, and I. Olivieri. 1998. Molecular phylogenetic approach for studying life-history evolution: the ambiguous example of the genus Medicago L. Proc. R. Soc. Lond. B 265:1141-1151.

Boutin, C., and J. L. Harper. 1991. A comparative study of the population dynamics of five species of Veronica in natural habitats. J. Ecol. 79:199-221.

Budyko, M. I. 1974. Climate and life. Academic Press, New York.

Charlesworth, B. 1994. Evolution in age-structured populations, 2nd ed. Cambridge Univ. Press, Cambridge, U.K.

Charnov, E. L., and W. M. Schaffer. 1973. Life history consequences of natural selection: Cole's result revisited. Am. Nat. 107:791-793.

Cole, L. C. 1954. The population consequences of life history phenomena. Q. Rev. Biol. 29:103-137.

Comstock, J. P., and J. R. Ehleringer. 1992. Plant adaptation in the Great Basin and Colorado Plateau. Great Basin Nat. 52:195-215.

Conti, E., D. E. Soltis, T. M. Hardig, and J. Schneider. 1999. Phylogenetic relationships of the silver saxifrages (Saxifraga, sect. Ligulatae Haworth): implications for the evolution of substrate specificity, life histories, and biogeography. Mol. Phylogenet. Evol. 13:536-555.

Correll, D. S., and M. C. Johnston. 1970. Manual of the vascular plants of Texas. Texas Research Foundation, Renner, TX.

Crawley, M. J. 1997. Plant ecology. 2nd ed. Blackwell Science Ltd, Oxford, U.K.

Daubenmire, R. 1968. Plant communities: a textbook of plant synecology. Harper and Row, New York. . 1978. Plant geography, with spec

Demesure, B., N. Sodzi, and R. J. Petit. 1995. A set of universal primers for amplification of polymorphic non-coding regions of mitochondrial and chloroplast DNA in plants. Mol. Ecol. 4: 129-131.

Dimmitt, M. A. 2000. Plant ecology of the Sonoran Desert region. Pp 129-151 in S. J. Phillips and P. W. Comus, eds. A natural 
history of the Sonoran Desert. Arizona-Sonora Desert Museum Press, Tucson, and Univ. of California Press, Berkeley.

Donoghue, M. J., and D. D. Ackerly. 1996. Phylogenetic uncertainties and sensitivity analyses in comparative biology. Philos. Trans. R. Soc. Lond. B 351:1241-1249.

Doyle, J. J., and J. L. Doyle. 1987. A rapid DNA isolation procedure for small quantities of fresh leaf tissue. Phytochem. Bull. 19: $11-15$.

Ehleringer, J. R. 1985. Annuals and perennials of warm deserts. Pp. 162-180 in B. F. Chabot and H. A. Mooney, eds. Physiological ecology of North American plant communities. Chapman and Hall, London.

Ehleringer, J. R., and R. K. Monson. 1993. Evolutionary and ecological aspects of photosynthetic pathway variation. Annu. Rev. Ecol. Syst. 24:411-439.

Evans, M. E. K. 2003. Life history evolution in evening primroses (Oenothera, Onagraceae): Cole's paradox revisited. Ph.D. diss. University of Arizona, Tucson, AZ.

Garcia, L. V. 2004. Escaping the Bonferroni iron claw in ecological studies. Oikos 105:657-663.

Gurevitch, J., S. M. Scheiner, and G. A. Fox. 2002. The ecology of plants. Sinauer, Sunderland, MA.

Hargreaves, G. H., and Z. A. Samani. 1982. Estimating potential evapotranspiration. ASCE, J. Irrigation and Drainage Division, 108:225-230.

Harvey, P. H., and M. D. Pagel. 1991. The comparative method in evolutionary biology. Oxford Univ. Press, Oxford, U.K.

Hautekeete, N.-C., Y. Piquot, and H. Van Dijk. 2002. Life span in Beta vulgaris ssp. maritime: the effects of age at first reproduction and disturbance. J. Ecol. 90:508-516.

Hershkovitz, M. A., and E. A. Zimmer. 1996. Conservation patterns in angiosperm rDNA ITS2 sequences. Nucleic Acids Res. 24: $2857-2867$.

Hickman, J. C. 1977. Energy allocation and niche differentiation in four co-existing annual species of Polygonum in western North America. J. Ecol. 65:317-326.

_ 1993. The Jepson manual: higher plants of California. Univ. of California Press, Berkeley.

Huelsenbeck, J. P., and F. R. Ronquist. 2001. MRBAYES: Bayesian inference of phylogeny. Bioinformatics 17:754-755.

Huelsenbeck, J. P., B. Rannala, and J. P. Masly. 2000. Accommodating phylogenetic uncertainty in evolutionary studies. Science 288:2349-2350.

Klein, W. M. 1962. New taxa and recombinations in Oenothera (Anogra). Aliso 5:179-180.

. 1970. The evolution of three diploid species of Oenothera subgenus Anogra (Onagraceae). Evolution 24:578-597.

Kusakawa, N., R. Uemori, K. Asaca, and I. Kato. 1990. Rapid and reliable protocol for direct sequencing of material amplified by the polymerase chain reaction. BioTechniques 9:66-72.

Lambers, H., F. S. Chapin, III, and T. L. Pons. 1998. Plant physiological ecology. Springer-Verlag, NewYork.

Law, R., A. D. Bradshaw, and P. D. Putwain. 1977. Life-history variation in Poa annua. Evolution 31:233-246.

Lesica, P., and J. S. Shelly. 1995. Effects of reproductive mode on demography and life history in Arabis fecunda (Brassicaceae). Am. J. Bot. 82:752-762.

Levin, R. A., W. L. Wagner, P. C. Hoch, W. J. Hahn, A. Rodriguez, D. A. Baum, L. Katinas, E. A. Zimmer, and K. J. Sytsma. 2004. Paraphyly in tribe Onagreae: insights into phylogenetic relationships of Onagraceae based on nuclear and chloroplast sequence data. Syst. Bot. 29:147-164.

Martins, W. C., and C. R. Hutchins. 1980. A flora of New Mexico. J. Cramer, Vaduz, Germany.

McGregor, R. L., and T. M. Barkley. 1986. Flora of the Great Plains. Univ. Press of Kansas, Lawrence.

Miranda, F., S. R. Coca, J. G. Espinoza I., and J. G. Lopez. 1991. Climatología de la región noroeste de México (Baja California, Baja California Sur, Sonora y Sinaloa). Part II. Temperatura: series de tiempo del valor mensual y estadísticas del año climatológico. Centro de Investigación científica y de educación superior de Ensenada, Ensenada, B. C., Mexico.
Moran, M. D. 2003. Arguments for rejecting the sequential Bonferroni in ecological studies. Oikos 100:403-405.

Mulroy, T. M., and P. W. Rundel. 1977. Annual plants: adaptations to desert environments. BioScience 27:109-114.

Munz, P. A. 1931. Studies in Onagraceae. VI. The subgenus Anogra of the genus Oenothera. Am. J. Bot. 18:309-327.

Neuhauser, M. 2004. Testing whether any of the significant tests within a table are indeed significant. Oikos 106:409-410.

Oyama, K. 1994. Ecological amplitude and differentiation among populations of Arabis serrata (Brassicaceae). Intl. J. Plant. Sci. 155:220-234.

Pavlik, B. M., and M. G. Barbour. 1988. Demographic monitoring of endemic sand dune plants, Eureka Valley, California. Biol. Conserv. 46:217-242.

Penman, H. L. 1956. Evaporation: an introductory survey. Neth. J. Agric. Sci. 4:7-29.

Ponce, V. M., R. P. Pandey, and S. Ercan. 2000. Characteristics of drought across the climate spectrum. J. Hydrol. Engin. 5: 222-224.

Purvis, A., and A. Rambaut. 1995. Comparative analysis by independent contrasts (CAIC): an Apple Macintosh application for analyzing comparative data. CABIOS 11:247-251.

Quintas, I. 2000. Eric II, Base de datos climatológica compactada, archivos y programa extractor. Instituto Mexicano de Tecnología del Agua, Progreso, Morelos, Mexico.

Raunkiaer, C. 1934. The life forms of plants and statistical plant geography, being the collected papers of C. Raunkiaer. Clarendon Press, Oxford, U.K.

Rees, M. 1994. Delayed germination of seeds: a look at the effects of adult longevity, the timing of reproduction, and population age/stage structure. Am. Nat. 144:43-64.

Robichaux, R. H., G. D. Carr, M. Liebman, and R. W. Pearcy. 1990. Adaptive radiation of the Hawaiian silversword alliance (Compositae-Madiinae): ecological, morphological, and physiological diversity. Ann. Mo. Bot. Gard. 77:64-72.

Roff, D. A. 1992. The evolution of life histories. Chapman and Hall, New York.

- 2002. Life history evolution. Sinauer, Sunderland, MA.

Schaffer, W. M. 1974. Optimal reproductive effort in fluctuating environments. Am. Nat. 108:783-790.

Schaffer, W. M., and M. Gadgil. 1975. Selection for optimal life histories in plants. Pp. 142-157 in M. Cody and J. Diamond, eds. The ecology and evolution of communities. Belknap, Cambridge, MA.

Schenk, H. J., and R. B. Jackson. 2002. Rooting depths, lateral root spreads and below-ground/above-ground allometries of plants in water-limited ecosystems. J. of Ecol. 90:480-494.

Schneider, J. M., and Y. Lubin. 1997. Does high adult mortality explain semelparity in the spider Stegodyphus lineatus (Eresidae)? Oikos 79:92-100.

Schwinning, S., and J. R. Ehleringer. 2001. Water use trade-offs and optimal adaptations to pulse-driven arid ecosystems. J. of Ecol. 89:464-480.

Shreve, F. 1951. Vegetation of the Sonoran Desert. Vol I. Carnegie Institute Publication 591. Carnegie Institute, Washington, DC.

Silvertown, J., and D. Charlesworth. 2001. Introduction to plant population biology. 4th ed. Blackwell Science Ltd., Oxford, U.K.

Smith, F. A., and E. L. Charnov. 2001. Fitness trade-offs select for semelparous reproduction in an extreme environment. Evol. Ecol. Res. 3:595-602.

Smith, S. D., R. K. Monson, and J. E. Anderson. 1997. Physiological ecology of North American desert plants. Springer-Verlag, Berlin.

Solbrig, O. T., and G. H. Orians. 1977. The adaptive characteristics of desert plants. Am. Sci. 65:412-422.

Solbrig, O. T., M. A. Barbour, J. Cross, G. Goldstein, C. H. Lowe, J. Morello, and T. W. Yang. 1977. The strategies and community patterns of desert plants. Pp. 65-104 in G. H. Orians and O. T Solbrig, eds. Convergent evolution in warm deserts. Dowden, Hutchinson and Ross, Stroudsburg, PA.

Spach, E. 1835. Synopsis Monographia Onagrearum. Annales des Sciences Naturelles; Botanique. Ser. 2. 4:164-178. 
Stearns, S. C. 1992. The evolution of life histories. Oxford Univ. Press, Oxford, U.K.

Suh, Y., L. B. Thien, H. E. Reeves, and E. A. Zimmer. 1993. Molecular evolution and phylogenetic implications of internal transcribed spacer sequences of ribosomal DNA in Winteraceae. Am. J. Bot. 80:1042-1055.

Taberlet, P., L. Gielly, G. Pautou, and J. Bouvet. 1991. Universal primers for amplification of three non-coding regions of chloroplast DNA. Plant Mol. Biol. 17:1105-1109.

Taylor, B., and A. Powell. 1982. Isolation of plant DNA and RNA. Focus 4:4-6.

Thompson, J. D., T. J. Gibson, F. Plewniak, F. Jeanmougin, and D. G. Higgins. 1997. The ClustalX windows interface: flexible strategies for multiple sequence alignment aided by quality analysis tools. Nucleic Acids Res. 25:4876-4882.

Tuljapurkar, S., and P. Wiener. 2000. Escape in time: stay young or age gracefully? Ecol. Modeling 133:143-159.

van Groenendael, J. M., and P. Slim. 1988. The contrasting dynamics of two populations of Plantago lanceolata classified by age and size. J. Ecol. 76:585-599.

Venable, D. L., C. E. Pake, and A. C. Caprio. 1993. Diversity and coexistence of Sonoran Desert winter annuals. Plant Species Biol. 8:207-216.

Verboom, G. A., H. P. Linder, and W. D. Stock. 2004. Testing the adaptive nature of radiation: growth form and life history divergence in the African genus Ehrharta (Poaceae: Ehrhartoideae). Am. J. Bot. 91:1364-1370.

Verhoeven, K. J. F., K. L. Simonsen, and L. M. McIntyre. 2005. Implementing false discovery rate control: increasing your power. Oikos 108:643-647.
Wagner, W. 1998. Species status for a Sonoran Desert annual member of Oenothera sect. Anogra (Onagraceae). Novon 8:307-310.

Welsh, S. L., N. D. Atwood, L. C. Higgins, and S. Goodrich. 1987. A Utah flora. Great Basin Nat. Mem. 9:430-471.

White, T. J., T. Bruns, S. Lee, and J. Taylor. 1990. Amplification and direct sequencing of fungal ribosomal RNA genes for phylogenetics. Pp. 315-322 in M. Innis, D. Gelfand, J. Sninsky, and T. White, eds. PCR protocols: a guide to methods and applications. Academic Press, San Diego.

Wiggins, I. L. 1980. Flora of Baja California. Stanford Univ. Press, Stanford, CA.

Wilbur, H. M. 1976. Life history evolution in seven milkweeds of the genus Asclepius. J. Ecol. 64:223-240.

Yang, Z. 1993. Maximum likelihood estimation of phylogeny from DNA sequences when substitution rates differ over sites. Mol. Biol. Evol. 10:1396-1401.

1994. Maximum likelihood phylogenetic estimation from DNA sequences with variable rates over sites: approximate methods. J. Mol. Evol. 39:306-314.

Young, T. P. 1981. A general model of comparative fecundity for semelparous and iteroparous life histories. Am. Nat. 118:27-36.

- 1984. The comparative demography of semelparous Lobelia telekii and iteroparous Lobelia keniensis on Mt. Kenya. J. Ecol. 72:637-650.

Young, T. P., and C. K. Augspurger. 1991. Ecology and evolution of long-lived semelparous plants. Trends Ecol. Evol. 6:285-289.

Zaykin, D. V., L. A. Zhivotovsky, P. H. Westfall, and B. S. Weir. 2002. Truncated product method for combining p-values. Genet. Epidemiol. 22:170-185.

Corresponding Editor: O. Pellmyr 